\title{
El pabellón de los mutilados
}

Francisco García Mendoza

Pontificia Universidad Católica de Chile

Antes de torcer en una esquina, la mujer le responde al militar: ¡Cállate, hueón!

La tanqueta continúa su marcha intransigente mientras ella sigue su tránsito hacia la plaza.

Milicos culiaos, vayan a huear a otro lado, manga de chuchesumadres.

Su garganta no cesa de producir y reproducir la rabia acumulada por décadas, el miedo.

Vayan a huear a otro lado, repite incansable, métanse su toque de queda por la raja.

La sucesión de agravios se replica desde la sintonía de otras gargantas. Gritar es un acto de liberación, de plantearse incontrarrestable en el espacio público intervenido por la disuasiva militar.

¡Milicos culiaos!

¡Asesinos culiaos!

¡Vendepatria culiaos!

¡Ladrones culiaos!

¡Milicos culiaos!

¡Hijos de puta!

Enfrentar las armas con el grito más recóndito, liberarlo de su contención de años, siglos. La extenuación de la garganta frente a las sílabas articuladas que signan una histórica acumulación represiva. Se disloca la palabra, teatraliza su expresividad. Su pulsión arremete indesmentible. La intensidad del grito descoloca y desbarata las posiciones de dominación. Cuando el cuerpo está totalmente desarticulado de sus posibilidades expresivas, es el grito el que sostiene la resistencia. 
Despertamos agazapados. Horizontales. Un solo organismo en cuarentena hospitalaria. Los dos como uno despertamos en la cama apenas contenedora de nuestras incipientes rebeldías.

La ciudad amanece y permanece inalterable, contenida por la inmanencia de los cerros. Rodeada de cumbres de las más diversas alturas. La ciudad en la que despertamos es también contenedora de la subversión que fluye por los cauces y las calles. Esa fuerza inagotable que fisura el territorio y horada la geografía buscando siempre nuevas posibilidades de extensión.

Despertamos incompletos, buscando la falta que nos designa y nos mantiene unidos en esta cama donde las huellas permanecen imborrables.

Hacinados permanecemos en estado de cuarentena, recluidos de las inclemencias externas. La calle aparece como espacio vigilado por los aparatos burocráticos y militares del Estado. Salir es exponerse a la irracional y desatada violencia ejercida constitucionalmente.

Nos contenemos. Rebasamos cada uno de los bordes que nos dibujan y definen como sujetos. Terciamos irreverentes cada vez que entablamos diálogo con las enfermeras. Nuestros límites pierden forma, nos volvemos corporalidad indeterminada, mutante, abierta e irreconocible por los sujetos que transitan fuera. Somos materia indisociable, nos situamos desde la indeterminación que ilumina y a la vez interroga sobre las nuevas potencialidades de relación. Se reconfigura entre nosotros el deseo, el afecto, las pulsiones que nos mueven ya como conjunto.

Nuestra rebeldía consiste en pensarnos y sabernos un nosotros, fuera del individualismo que mancilló a las luciérnagas que ven en la reagrupación la manera de resistir. Refundar la colectividad suprimida.

La noche galopa en sus explosiones.

Lejanas explosiones en la periferia.

La noche galopa militarizada.

La noche se extiende en el territorio nacional, ocupa cada uno de los recovecos de insubordinación. La noche obliga al silencio. La noche se concentra en uno de los puentes que cruza el río. Uno de los tantos puentes. El más cercano a la plaza. 
La noche se acostumbra. Se detiene la noche en el cruce peatonal que interviene el asfalto. Frío. Mudo a esas horas el asfalto la noche se prolonga. Se desliza sigilosa a ras de suelo y se extiende, todo lo abarca la noche que galopa.

Un aullido incierto, quejidos impalpables.

Cede la noche, abre su espacio. Un puente iluminado se dilata. Sombras lo recorren. Huyen las sombras aterradas del silencio.

Caen. Caen sombras al lecho del río. Pesadas sombras que golpean el cemento, mientras la noche iluminada galopa huyendo de ese puente.

Acabo de despertar.

Comienzo a bostezar y a ser consciente del cansancio corporal que me retiene inmóvil. Anoche, o hace unas horas, oí la balacera distante de una persecución. Disparos secos y temporalmente retardados en respuesta a una ráfaga automática de seis o siete descargas. Poco a poco se fueron difuminando en la distancia que se diluye en los márgenes de esta ciudad militarizada.

La multitud se recluyó. La plaza en donde millones y millones se reunieron ahora no es más que una explanada dislocada. Deambulan apenas los recuerdos individuales, la colectividad reprimida. Una o dos luciérnagas asoman tímidas a veces como destellando incesantes sus bengalas.

Una acidez interminable impregna estas sábanas compartidas. Una pierna cruza la mía y amenaza mi genitalidad exhausta y dolorida. La pierna también es suave. La pierna siente y reacciona a mis impulsos y reacomodaciones musculares.

Esto no es lo que me contaron sobre el amor. No me dijeron que era buscar su humedad por la noche, el espacio en donde encajar mis dedos en el abrazo corporal que se lanza como bengalas en una oscuridad incierta. Quiero dormir y más tarde estrujar y presionar mi genitalidad hasta el límite de lo posible, hasta los calambres, hasta la irrefrenable necesidad de levantarse a orinar. Quedarse errático frente al baño.

No es el amor, son los pactos de convivencia los que nos van a salvar.

Hace días, apenas un par, interminables caravanas de gente regresaban por la arteria a sus refugios periféricos, al límite del toque de queda avanzando hacia el sur. Siempre al sur. Ánimas murmurando una lengua ininteligible. Un cifrado clandestino que recorre la ciudad hacia el sur. 
Nosotros permanecemos tristes en el confinamiento mutuo de estas corporalidades que se aprehenden. Me doy vuelta en la cama para buscar un escape, una salida a ese cuerpo ácido que me excede. Esas piernas suaves y frías que me abarcan y reprimen. Me aprisionan con su amargor estancado. Estamos atrapados en el centro mismo de la disposición cardinal.

Fuerzas de seguridad.

Confinamiento y angustia.

Programa de reparación ocular.

Traumas oculares.

Heridos oculares.

Pérdida total del globo ocular.

Estallido ocular.

Pérdida del 95\% de la visión del ojo.

Evadir el espejo

No reconocerse sujetos heridos.

Espejearnos los cuerpos.

Asimilarnos los bordes, recorrer las honduras.

Estructurar la mirada cíclope.

Habitar el nuevo espacio de bidimensionalidad.

Dormir acurrucado dentro mío.

No hay sueños que nos basten esta noche.

Ni uno solo que nos arranque, que nos colme y se incruste en cada uno de los espacios. No hay sueños que nos basten esta noche. Ninguno que recorra estos dedos mugrosos de río. Callosos los dedos. Las bolsitas de género debajo de las uñas. La mugre en el fondo del cauce. Tu piel temblorosa de niño. Te hundes y nos arrastramos río abajo como si fluyéramos con el mismo río. Mis dedos mugrosos te recorren siguiendo el flujo que desorilla tus bordes fríos. Te palpo. Te sigo descendente y aferrados nos hundimos. Nos ahogamos en la intermitencia de este recorrer. Mis dedos se detienen. Busco tu ojo fijo. Pensamos los cuerpos en el río, las piedras que en el fondo se rozan inertes. Una caricia boca abajo, cerrados los ojos en el fondo. La mugre que se incrusta en sus dedos hinchados de agua mientras te 
recorro río abajo y tiemblas. Tiemblas como si el frío húmedo penetrara también tus huesos condenados.

No hay sueños que nos basten esta noche.

$\mathrm{Ni}$ uno solo hay que nos arranque.

Hace días las sirenas colman el espacio sonoro de este cuarto.

En las esquinas los soldados patrullan, deambulan frente a las botillerías.

Una tanqueta ronda la plaza. Da vueltas y más vueltas. No para y los semáforos siguen alternando entre el rojo y el verde. La tanqueta avanza en esa interminable ronda cíclica del patrullaje institucional.

En esta misma cama donde anoche dormimos, donde anoche no soñamos, la infinita circularidad del acoplamiento genital nos mantiene en estricto confinamiento.

Afuera, abajo, deambulan espectros en absoluto silencio. Desde la ventana podemos seguir sus pasos errantes. La noche lo cubre todo de una bruma quieta. Son ánimas, nos decimos, por eso nadie las molesta, por eso los militares no se acercan. Pueden verse, están ahí, pero no hay posibilidad alguna de interactuar con ellas. Hablan, pero nadie las escucha. Gritan, pero sus voces no son capaces de traspasar el umbral de su propio confinamiento. Ánimas enmudecidas en la inmaterialidad de su propia existencia. Ánimas que vagan indescifrables. Espectros que desafían indiferentes la épica vigilancia del quehacer militar.

Oímos disparar la noche

oímos murmullos de dolor

oímos, a lo lejos, inquietantes sirenas

oímos el tronar de los huesos

astillados huesos

oímos nuevamente el dolor

oímos, esta noche, todas las noches

oímos el derrumbe de las trizaduras

oímos pasos

oímos piedras

oímos el murmullo de las aguas 
inquietas aguas

oímos nuestros propios cuerpos

oímos palpitar la noche

las sirenas

las interminables sirenas

recorriendo las oímos

esta noche

el recuerdo de otras noches

una nube blanca

extrañamente blanca

espejeando el mismo cielo

cielo que se oculta

cielo que se pierde

cielo que devora

que vigila

que sospecha

el mismo cielo

teñido de amarillo

en la noche más profunda

oímos el desborde

oímos las piedras

llorar las piedras

oímos

otra vez oímos

alguien agoniza

un perdigón se incrusta

un ojo machacado

un ojo que no es ojo

que no será más ojo

nunca más un ojo

reventado de dolor

reventado de espanto

en la noche de sirenas 
oímos

esta vez oímos

perdigones contra piedras

en la impenetrable noche

de los ojos mutilados.

Despierto temprano. La frazada apenas nos cubre del frío.

Sus pies helados. Las sirenas.

El calor se nos arranca.

Se acomoda, busca un lugar más profundo en el colchón. Inconscientes casi los músculos se desplazan y tensan. Apenas se mueve, imperceptible. Bosteza, crujen las vértebras, reacomoda el cuello y los huesos truenan en la habitación.

Afuera el ruido es inestable. Un motor se aleja hasta perderse. Escombros contra el piso. Los días se parecen todos. Afuera las piedras junto al río. Las piedras inmutables que dan cuenta del estado de catástrofe en el que estamos. El toque de queda permanente, la circulación vigilada de los sujetos que huyen de sus propios pasos, el confinamiento obligado al que nos tienen sometidos.

Niño sin nombre.

Niña sin nombre.

Quedamos como cuerpos abandonados en el entramado hospitalario de la ciudad.

Nuestros rasgos se difuminan en la estrechez de los abrazos a los que nos aferramos buscando el último rastro de calor. Ese que se nos arranca por las cuencas vacías de los ojos.

No se ahonda en las vidas previas al hospital.

La niña está empeñada. Engendrar una vida que la salve del abismo en que se encuentra. El niño busca. Las complicidades de su madre en los bordes de la muchacha.

Este es el pabellón de los mutilados, de los niños no reclamados. Sujetos ajenos a la institucionalidad familiar, cuerpos olvidados, absolutamente desechables. 